\title{
Decent Work During the Pandemic: Indication and Profiling Matters
}

\author{
M.V. Simonova ${ }^{1, *}$, L.V. Sankova ${ }^{2}$, and F.I. Mirzabalaeva ${ }^{3}$ \\ ${ }^{1}$ Samara State University of Economics, Samara, Russia \\ ${ }^{2}$ Yuri Gagarin State Technical University of Saratov, Saratov, Russia \\ ${ }^{3}$ Plekhanov Russian University of Economics, Moscow, Russia
}

\begin{abstract}
The article is devoted to the study of theoretical and applied aspects of decent work during the period of unstable economy development associated with the pandemic. The aim of research is to identify key labor trends, determine valid indicators and analyze decent work profiles at the level of the world community, Russia and its regions. The authors analyzed the decent work profiles at the beginning and during the downturn of the pandemic; studied the components of decent work in the economy as a whole and at the regional level. Special attention is paid to the criteria of profiling, which determine the necessary investment directions and formats in ensuring decent work conditions in the country context. Indicators and an integral indicator of decent work, taking into account the conditions of the pandemic, including unemployment; expenditure in GDP and payments against the subsistence minimum; loss of working time due to restrictive measures; the proportion of workers transferred to remote employment; Wage change rate; occupational safety index and others are proposed. The materials can be of practical value for the employment policy directions development at the regional and Federal levels of Russia, taking into account the current epidemiological situation and employment digitalization strategic priorities.

Keywords: Decent work, Pandemic, Unemployment; Employment policy; Social welfare.
\end{abstract}

\section{Introduction}

The economy instability, as an immanent feature of its development, is projected on the labor and employment sphere, generating shocks of demand for labor, restructuring of employment by sector, remuneration monetary characteristics volatility, active employment policy's new programs updating, the population social welfare formats. The uniqueness of the instability initial period is largely determined by the trigger-coronavirus pandemic and the economic activity compression due to supply restrictions on many components of personal consumption, which in the past were not always affected by the recession [11].

The modern socio-economic space transformation in all countries of the world in the context of the COVID-19 pandemic has a direct impact on the subject field of decent work. It is conditioned with some factors. Firstly there are some changes in the labor market subjects' behavior. Secondly, the cycle of macroeconomic policy measures' impact on

*Corresponding author: m.simonova@mail.ru 
labour market indicators is accelerated. Thirdly, new social and occupational risks requiring protection are appeared. Fourth, all the key parameters of decent work that have been defined by ITO are transformed. The request for the definition of indicators of decent work and the analysis of developments in various countries, regions and sectors of the economy during the pandemic is formed.

Let's imagine the modern process of the economy functioning within the framework of the decent work discourse. The International Labour Organization treats decent work as productive work, which at the same time is free, safe, fairly paid, developing and not diminishing human dignity. In summary, the following blocks are proposed within the framework of the Concept of decent work, reflecting the main characteristics of decent work: employment; social welfare; respect for the rights of employees; social dialogue development.

Principles and standards of decent work are developed by foreign and domestic researchers (R. Anker, G. Fields, D. Guy, F. Egger, F. Bonnet, A. Chatenier, G. Standing, V. N. Bobkov, R. P. Kolosova, L. A. Kostin, etc.). Decent work programmes are being implemented in more than 40 countries around the world.

In the context of the pandemic, it is necessary to clarify approaches to the criteria and indicators of decent work, as well as to develop mechanisms for ensuring it for workers. It is necessary to take into account the following aspects: the limited statistical, methodological basis and tools for assessing and monitoring decent work in a pandemic due to the novelty of the problem, the lack of indicators and standards of decent work in a broader context - in relation to the digital transformation of the field of work and employment.

Digitalization of employment, which accelerated significantly during the pandemic, is the leading trend in the labor sector on the one hand, $[1,8,16,18]$, and the only possible mechanism for many companies operating under quarantine measures, on the other hand.

The matters of the coronavirus pandemic's impact on the work sphere have been highlighted in reports by the ILO and other international organizations. The ILO's preliminary assessment (March 2020) of the impact of COVID-19 on the global world of work indicates negative consequences. Unemployment, underemployment, and work poverty, which will require a coordinated and rapid response from government and interstate agencies, are among them [5]. Studies show different effects of the pandemic on workers in different sectors, levels of education, and gender characteristics in different workplaces [15]. Experts focus on the labor market and employment trends evolution during the COVID19 pandemic $[4,6,7,9]$, estimates of supply shocks from labor supply [14].

We propose an approach to the study of decent work as a mechanism for ensuring stability in the period before the pandemic and during the pandemic in the context of an unstable economy. The article will consider methodological issues of indication and profiling of decent work taking into account the influence of the coronacrisis, the limited traditional approaches to its assessment and proposed an integral indicator of decent work. The section "Results" compares a number of decent work indicators in pre-pandemic and pandemic situations at the international, national and regional levels. The grouping of regions of the Russian Federation by unemployment indicator is presented. The section "Discussion" discusses issues of profiling decent work, issues of remote and informal employment during the pandemic, international and Russian experience in implementing anti-crisis measures in the labor market. The Conclusion contains the main conclusions of the study and defines the directions of employment policy in modern conditions, taking into account the emerging regional profiles of decent work. 


\section{Methodology}

The issues of indication and determination of decent work's progress as a key condition for economic stability was at the centre of the ILO's attention even before the pandemic.

The approach to measuring decent work is used by the United Nations development Programme as one of the indicators of human development. To assess the implementation of the principles of decent work, 7 indicators were proposed: the share of employed in the total population; employment in the formal sector of the economy and the ratio of this indicator for women than men; the level of vulnerable employment and increased the ratio of women to men increased; the share of working poor in total employment; the unemployment rate depending on education level; level of child labour use; the duration of paid maternity leave. To rank OECD countries on indicators of decent work in industry, the following components were identified: gender inequality; employment; social dialogue and social protection [10]. To measure decent work, Federal State Statistics Service of the Russian Federation publishes the following indicators: the share of employed in the total population (\%), the unemployment rate (\%), the share of the informal sector in total employment (\%); the share of NEET youth (\%); the working poor (\%), and others.

We suggest grouping the criteria for describing decent work profiles reflecting pandemic conditions as follows:

- criteria determined by the influence of external factors. They include measures of fiscal and monetary policy that affect employment and employee health; business response to measures to support jobs and business activity, compensation for losses; effectiveness of regional management in keeping employment and supporting the income of the population;

- criteria determined by the institutional aspects for the labor market and employment functioning (labor legislation, employment policy, work of the Employment Services in pandemic conditions);

- criteria determined by the possibility of using the digital format of employment by organizations and employees;

- criteria reflecting the specifics of population social welfare during the pandemic (coverage, amount of payments, share of expenditures in GDP).

- criteria that reflect the interaction of the parties to the social dialogue (government, business, trade unions, NGOs) in protection of employment and safety in workplaces, income support.

To assess changes in work sphere, we suggest calculating decent work profiles and integrated decent work indices. After selecting the components for each specified criterion, the profile and index of decent work in the context of a pandemic are calculated. It seems that the choice of indicators of decent work should be based on the following principles: comparability of indicators; availability and completeness of statistical and empirical base; flexibility, the possibility of structuring by elements of decent work.

Taking into account both quantitative and qualitative parameters, we can propose the following formula for calculation of the integral indicator of decent work - Idw:

$\mathrm{Idw}=0,2(1$-Iur $)+0,3 \mathrm{Isw}+0,1(1$-Iwtl $)+0,1$ Isre $++0,1$ Isc $+0,1 \mathrm{Il}$ s $+0,05$ Ige $+0,05$ Isd

Iul-unemployment rate; Isw - social welfare indicator (complex indicator, including expenses in DGP share and size of the compensation in relation to living wage); Iwtl working time loss indicator due to restrictive measures (in percent); Isdw -share of employees transferred to remote employment format; Isc - salary changes indicator (share of employees getting the same wages as before pandemic); Ils - labour safety indicator (it is calculated as a share of employees working in conditions that meet standards and regulations, the proportion of employees covered by COVID protection measures is also 
taken into account); Ige - gender equality indicator; Isd - indicator, reflecting social dialogue efficiency.

The integral indicator of decent work during the pandemic will be defined as the weighted average of these groups of indicators. Each of the indicators takes values in the range from 0 to 1 , the sum of the weights must be equal to 1 . To calculate these indicators, you can use official statistics, as well as data from surveys and surveys (taking into account the quality parameters of decent work).

\section{Results}

Taking into account the limitations of statistics on a number of the proposed index components, consider the decent work profile based on available data. The analysis of regional problems in the decent work principles implementing revealed the main limitations and potential risk zones even in the period before the pandemic [17]. Compare the decent work indicators of the Russian Federation in the period before the pandemic and the situation with a number of decent work indicators in pandemic conditions. Analysis of the data of the Federal State Statistics Service of the RF shows that despite the positive trends in the change in a number of indicators of decent work, even before the pandemic, alarming dynamics remain. This also applies informal employment, inequality in income distribution. The proportion of NEET youth is also declining. It should be noted that it is the representatives of the informal sector who have found themselves in the most difficult situation in the context of the pandemic.

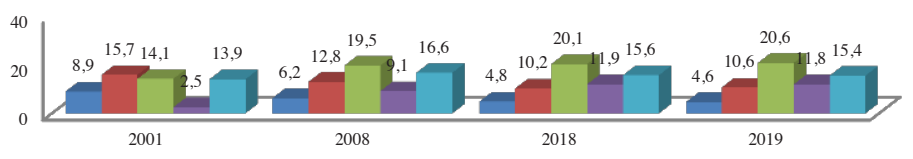

- M - Unemployment level, \%

M - Youth, which doesn't study, work and obtain professional skills at the age of $15-24$, in the total poulation size of the corresponding ageing group, $\%$ Informal sector share in the total employment, \%

- M - The State expenses for social policy (in \% to the Gross Domestic Product)

口 C - Inequality in income distribution: P90/P10

Fig. 1. Decent work indicators in Russia in 2001-2019

Source: Own processing

In the context of a pandemic, the instability rate is the most sensitive to changes in the socio-economic situation (Fig.2). In the period of April and May 2020, The Federal State Statistics Service of the Russian Federation fixes an increase in the indicators growth both of overall unemployment rate (from 4.6 to $6 \%$ ), and registered unemployment (from 1 to $2.8 \%)$. 


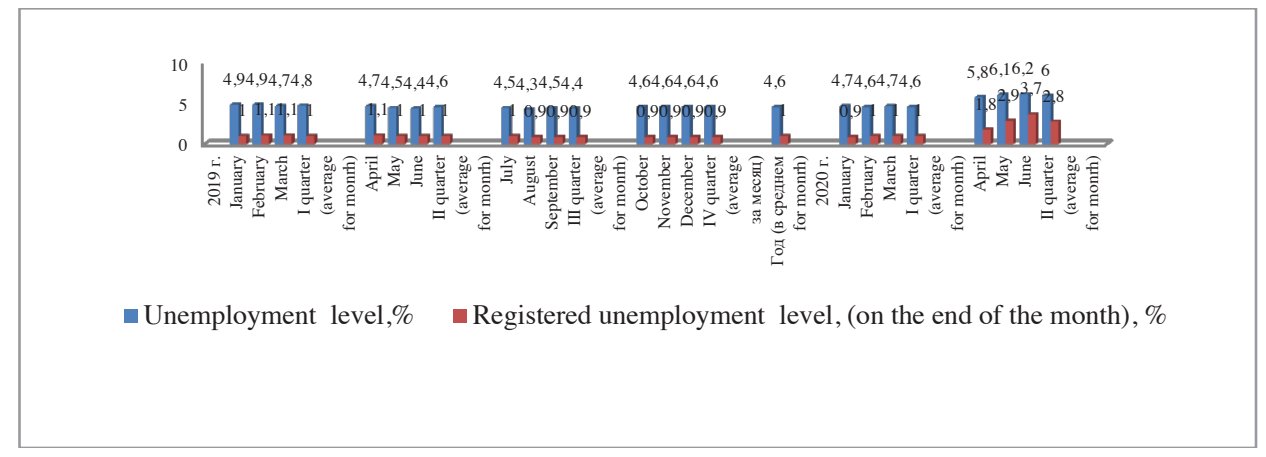

Fig. 2. Unemployment level dynamic in 2019- 2020

Source: Own processing.

In all previous periods of instability and crises, price and time adjustment in the Russian labor market prevailed over quantitative adjustment. This reduced the incentives of companies to release, contributed to the preservation of employment. During the pandemic period, these company strategies were also widely used.

Researchers identify the following changes in the registered labor market in the $2^{\text {nd }}$ quarter of 2020[3]:

- a significant increase in the share of citizens who have not previously worked and are looking for work for the first time, among the unemployed registered with the employment service. Thus, the total number of unemployed (aged 15 years and older) in June 2020 was 4.6 million people or $112.6 \%$ compared to the first half of 2019 , and the number of officially registered unemployed in the 1st quarter of 2020 was $179.1 \%$ compared to the first quarter of 2019; registered unemployment grew at a faster rate in relation to total unemployment (according to the ILO methodology), which increased by $31 \%$ over the same period (according to preliminary data from Rosstat) [3].

- increase in the share of young people aged 20 to 29 , as well as the share of unemployed citizens aged 30 to 49 in the structure of the unemployed;

- significant increase in the share of unemployed people who do not have basic General education, as well as unemployed people with basic General and secondary General education;

- exceeding the number of resumes over the number of vacancies.

In regional view decent work profiles are primarily formed by the employment block, which is reduced. In this context we have identified four groups of regions based on the unemployment rate (see table.1). The table shows regions in descending order of the unemployment rate. Before the pandemic period (January-March 2020), the minimum unemployment rate $(1.5 \%)$ was observed in Moscow, and the maximum was $26.6 \%$ (Republic of Ingushetia). In the $2^{\text {nd }}$ quarter of 2020, there is an increase in unemployment in all regions. The maximum value is still observed in Ingushetia (30.1\%), the minimum value-in Moscow (2\%). 
Table 1. Unemployment rate of the population aged 15 years and older in the regions of the Russian Federation, April-June 2020 (in \%)

\begin{tabular}{|c|c|}
\hline $\begin{array}{l}\text { Unemploy } \\
\text { mentrate, } \%\end{array}$ & Regions \\
\hline $2,0-5,4$ & $\begin{array}{l}\text { Magadan region, Smolensk region, Ryazan region, Kaliningrad region, Rostov } \\
\text { region, Orenburg region, Saratov region, Belgorod region, Leningrad region, } \\
\text { Sevastopol, Tyumen region without auth. districts, Samara region, Tambov } \\
\text { region, Kaluga region, Nizhny Novgorod region, Chukotka Autonomous district, } \\
\text { Voronezh region, Lipetsk region, Tula region, Tver region, Bryansk region, } \\
\text { Khabarovsk territory, Kamchatka territory, Republic of Tatarstan, Moscow } \\
\text { region, Tyumen region, Saint Petersburg, Yamalo-Nenets Autonomous district, } \\
\text { Moscow }\end{array}$ \\
\hline $5,5-8,7$ & $\begin{array}{l}\text { The Republic of Adygea, Yaroslavl region, Komi Republic, Kurgan region, } \\
\text { Murmansk region, Irkutsk region, Volgograd region,Astrakhan region, } \\
\text { Arkhangelsk region, Arkhangelsk region without auth. districts, Republic of } \\
\text { Sakha (Yakutia), Chuvash Republic, Jewish Autonomous region, Udmurt } \\
\text { Republic, Oryol region, the Republic of Mari El, Krasnoyarsk territory, Pskov } \\
\text { region, the Republic of Crimea, Sverdlovsk region, Chelyabinsk region, Perm } \\
\text { region, Kemerovo region, Vologda region, Novosibirsk region,Vladimir region, } \\
\text { Krasnodar territory, the Republic of Bashkortostan, Altai territory, Amur region, } \\
\text { Stavropol territory, Kirov region, Kostroma region, Ivanovo region, Primorye } \\
\text { territory,Kursk region, Penza region, Novgorod region, the Republic of Mordovia, } \\
\text { Ulyanovsk region, Sakhalin region }\end{array}$ \\
\hline $9,4-11,0$ & $\begin{array}{l}\text { the Republic of Buryatia, the Republic of Kalmykia, the Republic of Khakassia, } \\
\text { Omsk region, TRANS-Baikal territory, Tomsk region, the Republic of Karelia }\end{array}$ \\
\hline $12,3-30,1$ & $\begin{array}{l}\text { The Republic of Ingushetia, the Republic of Tyva, the Republic of North Ossetia- } \\
\text { Alania, the Republic of Dagestan, the Republic of Karachay-Cherkessia, the } \\
\text { Republic of Kabardino-Balkaria, Chechen Republic, Altai Republic }\end{array}$ \\
\hline
\end{tabular}

Source: Rosstat.

Pandemic conditions are changing the portrait of an unemployed person. In particular, his comparison in the $1^{\text {st }}$ and $2^{\text {nd }}$ quarters of 2020 shows significant changes in age, professional qualification, and educational aspects [3]. This perspective allows us to judge the shortage of decent work for different population groups.

Trade, construction, services have been more affected by the significant deterioration of decent work profiles during the pandemic. To a greater extent, the problem of reducing employment and declining income due to the liquidation of organizations affected trade; repair of motor vehicles and motorcycles (86.3 liquidated organizations per 1000 organizations in the 1st half of 2020), construction (79.1), transportation and storage (62.9). Trade, construction, and services were more likely to experience a significant deterioration in the "profiles" of decent work during the pandemic.

Wages have always been one of the key indicators of decent work. During the pandemic (for the three spring months of this year, which included a period of non-working days and severe economic restrictions, the total wage Fund for employees decreased by $4.7 \%$ compared to last year's spring - to RUB 6.8 trillion, (according to FinExpertiza). The peak collapse was recorded in April (more than 20\%).This process involves a direct reduction in salaries or allowances, a reduction in the number of employees, and the transfer of parttime employees.

Let us turn to the international aspect. Consider the dynamics of the unemployment rate in a number of OECD countries before and during the pandemic (figure 3 ). 


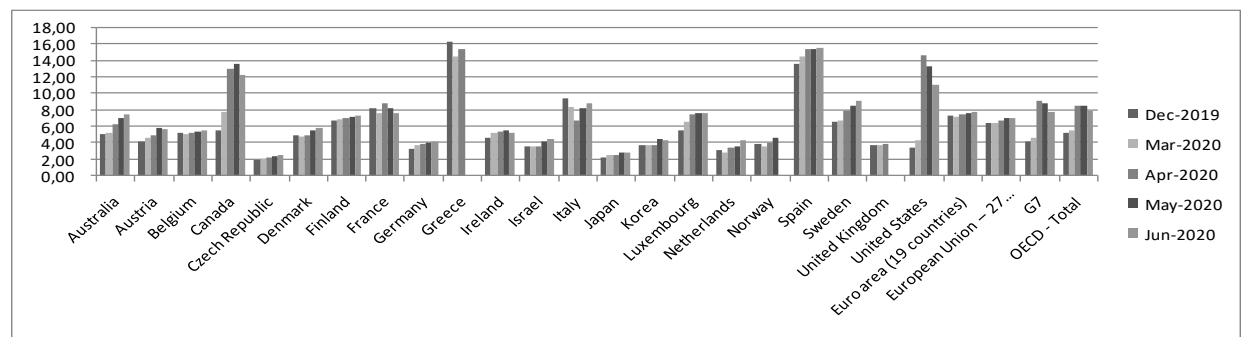

Fig. 3. Unemployment rate dynamics in several countries of OECDin December, 2019 - June 2020 Source: Own processing based on https://stats.oecd.org/index.aspx?queryid=36324.

Analysis of the data shows, first, an increase in the unemployment rate in all the countries represented; second, the presence of common patterns in the dynamics of unemployment in recent years in many countries; and third, different rates of the spread of the pandemic, restrictive measures and the effectiveness of policies to preserve and protect employment in countries. For example, the highest unemployment rate in June 2020 was observed in Spain (15.6\%), the lowest - in the Czech Republic (2.6\%). At the same time, according to forecasts, the average employment rate in these countries in 2020 will be $4.1-$ $5 \%$ lower than in 2019. The share of working people is expected to remain below pre-crisis levels even at the end of 2021.

According to the ILO, by the end of May 2020, more than 90 countries had introduced or announced fiscal measures totaling more than $\$ 10$ trillion, while the same number of countries reduced interest rates after the outbreak. The approved international financing for health and social protection amounted to $\$ 46.9$ billion, of which $51 \%$ is a soft loan, $46 \%$ is a loan. According to ILO estimates, from the point of view of institutions, the IMF represents 47.3\%, 15.4\% - the World Bank, 14.2\% - the Asian Development Bank.

Considering the problem of financing anti-crisis measures in Russia, we note that assistance packages worth more than 2 trillion rubles have been developed and are being implemented, which primarily affects the field of employment and income. To restore the economy, a three-tier program has been developed until 2021, which includes the "adaptation stage", the "recovery stage" and the "active growth" stage. At each of these stages, the objectives of employment policy and the measures applied may vary.

\section{Discussion}

In the context of a pandemic, traditional criteria and parameters for decent work are becoming more informative. In particular, the total indicator of the impact of the COVID19 crisis on the labor market is the loss of working time estimated by the ILO using the forecasting model [13]. The amount of losses is determined by the institutional structure of national labor markets.

In this context, we are faced with differences in the assessment of the components of "losses" in the labor market and in employment, which allows us to form an idea of the profile of decent work in a particular country or region. For example, the traditional indicator of the decent work deficit is unemployment, which has increased to some extent in all countries. However, the ILO focuses on the loss of working time. At the same time, the structure of working time losses can include the following components: reduction of the average working time per week; the presence of workers formally present at work, but not really working; unemployment; leaving the labor market.

In terms of changing decent work profiles, there is a significant cross-country differentiation in the pattern of time losses. For example, in Great Britain and Northern Ireland, the loss of working hours was mainly due to reduced working hours and the 
number of workers who were employed but not employed. At the same time, the share of the unemployment component in the structure of labor losses was very small. In countries with stringent measures to contain unemployment, there has been little growth. There has been a significant loss of jobs in Canada, leading to both unemployment and "unnecessary" employment. Finally, in the US, job losses amounted to about $2 / 3$ of the reduction in working hours, and unemployment accounted for almost half of this reduction.

As shown by international practice and the ILO's activities in the context of economic shocks, it is the issues of decent work that are becoming a priority for the fight against COVID-19 on the basis of international labor standards. In particular, the following measures are key ones in various countries of the world:

First, protecting workers in the workplace; strengthening occupational safety measures; various job adaptations formats (such as telework); preventing discrimination and exclusion; ensuring access to health for all groups of workers; and increasing access to paid leave.

Second, stimulating labor demand: active fiscal policy; enabling and adaptive monetary policies; lending and financial support to specific sectors, including health care. Fiscal policy measures in advanced economies account for 88 per cent of global financial stimulus, accounting for an average of 5 per cent of GDP.

Third, support for employment and income through expansion of social welfare for all; various formats of employment retention (short-term work, paid leave, etc.), subsidies, financial/tax benefits for small and medium-sized businesses.

In terms of overcoming the economic consequences of the new coronavirus infection, prepared By the government of the Russian Federation, the following measures to support income and employment should be highlighted: an interest-free salary loan (coverage-805 thousand people); a $2 \%$ salary loan with the possibility of write-off (coverage-3.5 million employees); financial assistance to businesses (in April and may - 3.3 million people will keep their salaries); deferred and reduced tax and insurance payments for small and medium-sized businesses (in the affected industries, 3 million people will be affected); for all industries, halving insurance premiums for salaries above the minimum wage (coverage of more than 20 million people); preferential loans to system-forming enterprises to maintain working capital and preserve jobs (coverage -911 thousand employees); increasing the minimum amount of sick leave payments per month-possible coverage- 2.3 million people; increasing the maximum amount of unemployment benefits; additional benefits for families where parents are unemployed;additional benefits for families with children (up to 1.5 years, up to 3 years, unemployed with children under 18 years; families in need for children 3-7 years old, etc.); participation in temporary employment programs, assistance to self-employment, distance learning, advanced vocational training, compensation to employers for partial remuneration of employees dismissed from other organizations due to liquidation or reduction - 67 thousand people.

In the context of the pandemic, employment in the informal sector is most severely affected. However we have to take into account the fact that, during the recovery period, informality is rapidly recovering.

The next aspect to pay attention to is the possibility of remote employment in the context of a pandemic. According to an analytical report by the Russian Public Opinion Research Center and Social Business Group, the share of Russians working remotely during the self-isolation regime due to coronavirus has increased eight times. The main part of them are specialists with higher education working in the public sector $(60 \%$, of which $47 \%$ have switched to remote work completely), and $13 \%$ - partially. Among specialists with higher education employed in the commercial sector, $51 \%$ of respondents switched to "remote". At the same time, there is a high differentiation of remote employment by region (in Moscow and St. Petersburg-29\%, in rural areas - 10\%). According to RBC, only $34 \%$ of 
companies switched to remote operation in the affected regions of Russia. Amendments to the law are being developed to legalize this format of work in the future, which allows us to speak about the institutionalization of key changes in decent work standards. The possibility of prolongation of this format for the post-pandemic period forms a request to assess an individual's satisfaction with their work. According to a study by Colliers International, conducted in Europe and the Middle East, $45 \%$ of office employees want to return from a remote location: they are not comfortable working at home. About $65 \%$ of respondents said that they are more used to working in the office.

\section{Conclusion}

The authors analyzed indicators and profiles of decent work and proposed an approach to calculating its integral index during the pandemic. Based on the index proposed by the authors, it is possible to determine the profiles of decent work at the national and regional levels, which will allow developing a set of measures to ensure employment and protect the population in conditions of economic instability, taking into account existing opportunities. It was noted that the differentiation of regions and sectors of the Russian economy according to the profiles of decent work has deepened. There is a need for flexibility or change of approaches at different stages in joint efforts to overcome the pandemic [11]. The study emphasizes that decent work is an institutional, economic and organizational issue.

Changes in decent work profiles will be determined largely by the effectiveness of measures to support unemployed and small and medium-sized businesses, as well as opportunities for rapid economic recovery (saving and generating new jobs). Indicators of decent work will be determined by accurate termination of support facilities at all stages of the recession.

As unemployment becomes one of the key indicators of the state of the labor sector during the pandemic, the transformation of institutions in the labor market takes on a special role. Interregional cooperation of employment services can help: to smooth out the shortage of vacancies in the region based on expanding remote operation formats in other regions; to allocate the resources of the territorial mobility assistance program; to create temporary and seasonal jobs as a buffer to unemployment, etc.

Decent work in the post-pandemic period should go in two ways and take into account short-term and long-term effects. New jobs need to meet decent work standards in terms of designated criteria and national labour standards. At the same time, it is necessary to implement the principles of decent work in the field of job security, wages, security, social protection, gender equality and access to social dialogue in existing jobs.

It seems that one of the productive areas of further study of the problem is the close connection of indicators of decent work with poverty. The decline in income, the increase in unemployment during the pandemic generates an increase in poverty in all countries; require the development of urgent measures to support the income of the population, investment in human capital. There is a need to explore the experiences of different countries in generating and sustaining income in pandemic conditions [12] and scale up good practices.

Declining incomes and rising unemployment during the pandemic generate an increase in poverty in all countries, and require the development of urgent measures to support the population's income and investment in human capital [12].

When analyzing indicators of decent work, it should be taken into account that the situation with the coronavirus pandemic (which is certainly a force majeure factor) cannot cancel out (although it can partially correct) the long-term trends and problems that have developed in the Russian labor market, and will require greater flexibility and adaptability from the state employment service. 


\section{References}

1. Agrawal, A., Horton, J., Lacetera N., Lyons, E. Digitization and the Contract Labor Market: A Research Agenda. Economic Analysis of the Digital Economy /A. Goldfarb, Sh. M. Greenstein, and C. E. Tucker, ed. http://www.nber.org/chapters/c12988(2015)

2. Alfaro,L., Becerra,O., Eslava, M. EMES and COVID-19: Shutting Down In A World Of Informal And Tiny Firms, Working Paper 27360 http://www.nber.org/papers/w27360(2020)

3. Antonova G.V., Mirzabalaeva F.I., Bondarchuk A.G. Unemployed portrait transformation at the registered market under impact of institutional and economic factors. Labour Economics. 7(8). doi: 10.18334/et.7.8.110781.

4. Baker, S., Bloom, N., Davis S. J. \& Terry St.J. COVID-Induced Economic Uncertainty. Working Paper 26983http://www.nber.org/papers/w26983(2020)

5. Cajner, T., L. D. Crane, R. A. Decker, A. Hamins-Puertolas, and C. Kurz (2020). Tracking Labor Market Developments During theCOVID-19 Pandemic: A Preliminary Assessment. Finance and Economics Discussion Series (2020)

6. Coibion, O., Gorodnichenko, Y., and Weber, M. Labor Markets During the COVID-19 Crisis: A preliminary view. NBER w27017. (2020)

7. COVID-9 and World of Work: Impacts and Responses, 18 March. URL: ilo.org/global/

8. Digital Labour Platforms and the Future of Work: Towards Decent Work in the Online World and the Future of Work: Towards Decent Work in the Online World URL: https://www.ilo.org/wcmsp5/groups/public/---dgreports/---dcomm/--publ/documents/publication/wcms_645337.pdf

9. Furceri, D, P Loungani, J D Ostry, \& Pizzuto, P. COVID-19 will Raise Inequality if Past Pandemics are a Guide. (2020)

10. Gay, D. Decentwork: concepts and indicators. International labour survey. T. 142. №1-2. 2003. M., C. 3-38. (2004)

11. Grigoriev, L.A., Pavlushina, V.A. Musychenko, E.Ye. Drop in the World Recession 2020. Economics Issues, 5,5-24. (2020)

12. Han, J., Meyer B. D. ,Sullivan, J. X. Income And Poverty In The COVID-19 Pandemic.Working Paper 27729http://www.nber.org/papers/w27729 (2020)

13. ILO Monitor: COVID-19 and the World of Work. Fifth edition. Updated Estimates And

Analysis. https://www.ilo.org/wcmsp5/groups/public/@dgreports/@dcomm/documents/briefingn ote/wcms_749399.pdf

14. Leibovici, F., Santacreu, A.M., \&Famiglietti, M. Social Distancing And ContactIntensive Occupations. On the Economy, St. Louis FED. (2020)

15. Montenovo, L., Xuan, J., Felipe, L, Schmutte, R., Simon, K., Weinberg, B., Coady, W. Determinants Of Disparities In COVID-19 Job Losses //Working Paper 27132. http://www.nber.org/papers/w27132 (2020)

16. Non-Standard Forms Of Employment: Resent Trends And Future Prospect European Foundation for the Improvement of Living and Working Conditions / Background paper for Estonian Presidency Conference "Future of Work: Making It e-Easy", 13-14 September. (2017)

17. Simonova, M. V., Sankova, L. V., Mirzabalaeva, F. I., Shchipanova, D. Y., \& Dorozhkin, V. E. Assessment problems and ensuring of decent work in the Russian regions. International Journal of Environmental and Science Education, 11(15), 76087626. (2016). 
18. Ziemann, V. Inclusive Labour Markets In The Digital Era: The case of Austria, OECD Economics Department Working Papers,WP-17-143.OECD Publishing, Paris. URL: http://dx.doi.org/10.1787/c2331c20-en. (2017) 